\title{
Doğrusal Yükleri Besleyen Şebeke Bağlantılı PV/Akü Sisteminin Tasarımı ve Tam/Kısmi Gölgelenme Durumlarında Performans Analizi
}

\author{
Kemal AYGÜL ${ }^{1}$, Tuğçe DEMİRDELEN², Mehmet TÜMAY ${ }^{2}$ \\ ${ }^{1}$ Çukurova Üniversitesi, Mühendislik Fakültesi, Elektrik Elektronik Mühendisliği Bölümü, \\ Adana \\ ${ }^{2}$ Adana Alparslan Türkeş Bilim ve Teknoloji Üniversitesi, Mühendislik Fakültesi, Elektrik \\ Elektronik Mühendisliği Bölümü, Adana
}

Geliş tarihi: 21.01.2019 Kabul tarihi: 28.06.2019

$\ddot{O} z$

Yenilenebilir enerji kaynaklarının kullanımı son yıllarda hızla artmaktadır. Bu durum sonucunda PV paneller ile günlük hayatta birçok uygulamada karşılaşılmaktadır. PV sistemlerin performansı çevre ve hava durumu gibi etmenlerden büyük oranda etkilenmektedir. Buna örnek olarak bulutlar, tozlanma, kar gibi nedenlerle meydana gelen gölgelenme veya kısmi gölgelenme durumlarının PV sistemlerin maksimum güç noktalarında çalışmasına neden olması gösterilebilir. Bu çalışmada bu durumun sonuçlarını incelemek üzere şebeke bağlantılı ve doğrusal yükleri besleyen bir PV/Akü sisteminin modellemesi yapılmıştır. Önerilen sistemin PSCAD ile benzetim çalışmaları yapılmış ve farklı gölgelenme senaryoları için performansı incelenmiştir. Benzetim çalışmaları sonucunda PV sistemin maksimum güç noktası izlemesi (MPPT) için kullanılan hata \& gözlem (P\&O) algoritmasının PV sistemin yerel maksimum noktalarında takılıp düşük verimle çalıştığı gözlenmiştir.

Anahtar Kelimeler: Fotovoltaik, Akü, Kısmi gölgelenme, Maksimum güç noktası izleme

\section{Modeling and Performance Analysis of Grid Tied Photovoltaic Panel/Battery System Feeding Linear Loads on Complete/Partial Shading Conditions}

\begin{abstract}
The use of renewable energy sources has been increasing rapidly in recent years. As a result of this situation, PV panels are encountered in many applications in daily life. The performance of PV systems is greatly influenced by factors such as the environment and the weather. Examples include shading or partial shading conditions due to clouding, dusting and snow that cause PV systems not to operate at maximum power points. In this study, in order to analyze the results of these conditions modelling of a grid connected PV/Battery system feeding linear loads was performed. The proposed system simulated via PSCAD and the performance analysis of the system under different shading scenarios was conducted. As a result of
\end{abstract}

*Sorumlu yazar (Corresponding author): Tuğçe DEMIRDELEN, tdemirdelen@adanabtu.edu.tr 
simulation studies, it is observed that perturb and observe $(\mathrm{P} \& \mathrm{O})$ algorithm used for maximum power point tracking was stuck at local maximum power points and the PV system operated at low efficiency.

Keywords: Photovoltaic, Battery, Partial shading, Maximum power point tracking

\section{GíRiş}

Geleneksel enerji kaynaklarının neden olduğu çevre kirliliği ve bu kaynakların tükenmekte olması nedeniyle güneş enerjisi gibi temiz ve tükenmez enerji kaynaklarına olan ilgi son dönemde giderek artmaktadır. Fotovoltaik (PV) hücreler, fotovoltaik etki ile güneş enerjisini elektrik enerjisine dönüştürmek için kullanılan başlica elemanlardan biridir. PV hücrenin akım ve gerilim seviyesinin düşük olması nedeni ile $\mathrm{PV}$ hücrelerin seri ve paralel bağlanması sonucu PV paneller, PV panellerin seri ve paralel bağlantı kombinasyonları ile de PV dizinler oluşturulur. Paralel bağlantı ile çıkış akımının, seri bağlantı ile çıkış geriliminin artırılması sağlanmaktadır. PV hücrelerin çıkış akım, gerilim ve güç değerleri ışınım yoğunluğu ve sıcaklık gibi parametrelere bağlı olduğundan dolayı bu parametreler değiştikçe PV sistemin akım, gerilim ve güç değerleri de değişiklik göstermektedir.

Güneș 1șınları PV dizini olușturan panellere eșit yoğunlukta geldiği zaman PV dizinin çıkış güç eğrisinde bir adet maksimum güç noktası gözlenir. Ancak bulut, tozlanma gibi nedenlerle 1şınım yoğunluğu PV dizin içerisindeki bazı panellerde az, bazı panellerde daha fazla olduğu zaman PV dizinin çıkış güç eğrisinde birden fazla maksimum güç noktası gözlenir. $\mathrm{Bu}$ durum kısmi gölgelenme durumu olarak isimlendirilir. Kısmi gölgelenme durumunda Şekil 1'de görüldüğü gibi global maksimum güç noktasının (GMPP) yanında yerel maksimum güç noktaları (LMPP) da gözlenir. Değişen sıcaklık ve sşınım yoğunluğu değerlerine karşın PV sistemi maksimum güç noktasında çalıştırmak önem arz etmektedir. Bu amaçla farklı yöntemler uygulanarak maksimum güç noktası takibi yapılmaktadır. [1,2] numaralı makalelerde homojen ışııım yoğunluğu ve kısmi gölgelenme durumları için kullanılan geleneksel ve güncel maksimum güç noktası izleme yöntemleri incelenmiş ve bu yöntemlerin avantaj ve dezavantajları tartışılmıştır.
Şekil 2'de gölgeli ve gölgeli olmayan hücrelerin akım-gerilim eğrisi gösterilmiştir. PV dizindeki gölgeli bir hücre seri bağlı olduğu gölgeli olmayan diğer hücreler ile aynı akım değerinde çalışmak zorunda olduğu için ters gerilim bölgesinde çalışmaya zorlanır. Bir hücrenin ters gerilim bölgesinde çalışması ise güç kaynağı yerine yük gibi davranıp güç tüketmesine neden olmaktadır. Bir süre ters gerilim bölgesinde çalışan hücre ısınarak açık devre haline gelir. Bu olaya sıcak yüzey etkisi adı verilmektedir. Bu etki by-pass diyotları kullanılıp ilgili hücreden ters akım geçmesini engelleyerek önlenmektedir. Kısmi gölgelenme durumunda PV sistemin çıkış güç karakteristiğinde oluşan çok tepeli karakteristiğin nedeni de by-pass diyotlardır.
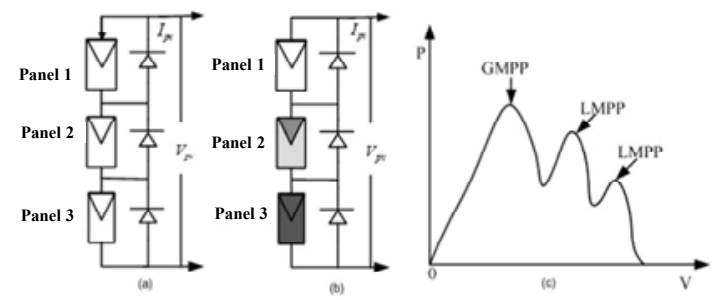

Şekil 1. (a) Homojen 1şınım yoğunluğu ve, (b) kısmi gölgeli durumdaki hücreler, (c) Kısmi gölgelenme durumundaki Gü̧̈Gerilim (P-V) eğrisi [1]

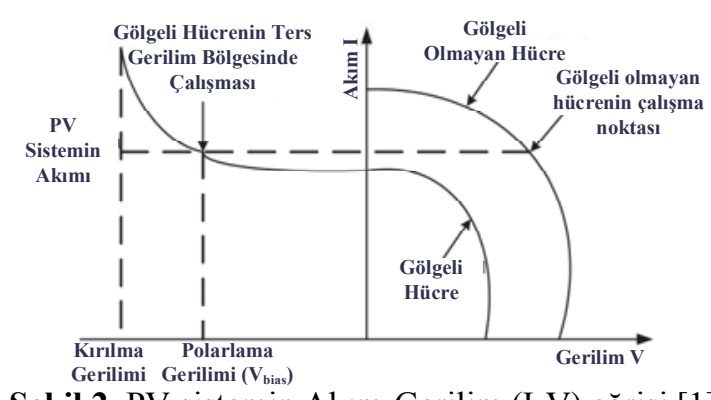

Şekil 2. PV sistemin Akım-Gerilim (I-V) eğrisi [1]

$\mathrm{Bu}$ çalışmada doğrusal yükleri besleyen ve şebeke bağlantılı bir PV/Akü sisteminin modellemesi ve 
farklı gölgelenme ve sıcaklık senaryoları için performans analizi PSCAD programı ile benzetim çalışmaları yapılarak gösterilecektir.

\section{2. ÖNCEKİ ÇALIŞMALAR}

Son dönemde PV panellerin tam ve kısmi gölgelenme durumlarındaki maksimum güç noktası takibi ve PV panellerin akü ile birlikte kullanıldığı devre yapıları ile ilgili birçok çalışma yapılmıştır.

Guichi ve arkadaşları [3] hibrit güç üretim sistemlerinde kullanılacak fotovoltaik sistemlerin homojen ışınım yoğunluğu ve kısmi gölgelenme koşulları için maksimum güç noktasında veya sınırlandırılmış güç modunda çalıştırılması için bir kontrol yöntemi önermişlerdir. Normal çalışma koşullarında maksimum güç noktası izleme (MPPT) için parçacık sürü eniyileme (PSO) yöntemi kullanılırken PV sistem tarafından üretilen güç, depolama ünitesinin kapasitesini ve yüklerin talebini aştığında sistemi orta güç modunda çalıştırmak için yazarlar tarafindan önerilen algoritma kullanılmıştır.

Goud ve arkadaşları [4], kısmi gölgelenme durumunda GMPP takibini (GMPPT) yapmak için iki farklı MPPT yöntemi kullanarak hibrit bir GMPPT yöntemi önermiştir. Önerilen yöntemin performansı benzetim çalışmaları ve deneysel veriler ile test edilmiştir. Farzaneh ve arkadaşları [5] kısmi gölgelenme durumlarında çalışan PV sistemler için geliştirilmiş ateşböceği algoritması ile GMPP takibi yapmayı önermiştir. Önerilen algoritma ile ateşböceği, PSO ve Hata ve Gözlem (P\&O) algoritmalarının performansları karşılaştırılmış ve önerilen algoritmanın ateşböceği, PSO ve P\&O algoritmalarından daha iyi bir performans gösterdiği belirtilmiştir.

Tang [6], bir gemi üzerine kurulan PV paneller ve aküyü içeren bir sistemin farklı gölgelenme koşulları için GMPP takibinde kullanılmak üzere "Decentralizing and coevolving differential evolution" (DCDE) ad1 verilen bir algoritma kullanmıştır. Bu algoritmanın performansı sayısal hesaplamalar ve deneysel veriler ile doğrulanmıştır.
Ramyar ve arkadaşları [7] kısmi gölgelenme durumlarında MPPT için yeni bir yöntem önermiş ve bu yöntemin performans analizini benzetim çalışmaları ve deney sonuçlarıyla sunmuştur.

Belhaouas ve arkadaşları [8], PV panellerin elektriksel bağlantısını değişmeden birbirine komşu hücrelerin yerlerinin değiştiği farklı kombinasyonlar ile kısmi gölgelenme durumlarında gölgeyi PV dizin üzerinde dağıtarak LMPP'lerin oluşmasını engellemeyi amaçlamıştır. Farklı gölgelenme senaryolarında bu bağlantı kombinasyonlarının performansı incelenmiş ve bu bağlantı şekillerinin kullanılmasının sistemin performansını artıracağı belirtilmiştir.

Wang ve arkadaşları [9] kısmi gölgelenme durumlarında GMPPT için "the search-skip-judge global MPPT" (SSJ-GMPPT) ve "rapid global MPPT" (R-GMPPT) adı verilen iki algoritma önermiştir. Deney sonuçlarıyla SSJ-GMPPT kullanılarak tüm gölgelenme durumlarında isabetli güç noktası izleme yapılabildiği, R-GMPPT kullanılarak hızlı bir şekilde maksimum güç noktasına ulaşılabildiği gösterilmiştir. Pati ve arkadaşları [10] şebeke bağlantılı bir PV sistem üzerinde MPP izleme için fibonacci arama yöntemi kullanmış ve ayrıca aktif/reaktif güç filtresi gören evirici aracılığı ile sistemin güç kalitesini artırmayı amaçlamıştır. Sistemin performansı benzetim çalışmaları ile test edilip sonuçları sunulmuştur.

Ghasemi ve arkadaşları [11] kısmi gölgelenme durumunda MPP izleme için iki aşamalı bir yöntem önermiştir. İlk aşamada kısmi gölgelenmenin varlığ1 tespit edilip daha sonra önerilen bir algoritma ile GMPP tespiti amaçlanmıştır. GMPP tespit edilmesinden sonra tekrar P\&O algoritması devreye alınarak MPP'deki küçük değişikliklerin takip edilmesi sağlanmıştır.

Sabillon ve arkadaşları [12], evsel yüklerin bağlı olduğu elektrik şebekesine bağlı olarak çalışan PV ve aküleri içeren bir sistemin elektrikli araçların şarjı için optimum bir şekilde kullanılmasını düzenleyen bir yöntem önermiştir. Önerilen sistemin performansı 107 noktalı bir dağıtım sisteminde test edilip performans sonuçları sunulmuştur. 
Hassan ve arkadaşları [13] elektrik ihtiyacı şebeke bağlantılı PV-Akü sistemi ile, şebekeye satış tarifesi üzerinden sağlanan bir müşterinin olduğu sistemi incelemiştir.

Numbi ve arkadaşları [14] şebeke satış tarifesinde çalışan bir PV-Akü sistemi önermiş ve bu sistem için optimum enerji modeli bulmayı amaçlamıştır. Sistemin enerji akışı, akü şarj durumu gibi parametreler benzetim çalışması ile incelenip sonuçları sunulmuştur.

Kumar ve arkadaşları [15] tek sensör tabanlı bir MPPT yöntemi kullanarak PV sistem ile akü şarj etmek üzere bir plan önermiştir. Ayrıca kısmi gölgelenme durumunda MPPT için "mathematicsbased hybrid Cauchy and Gaussian sine cosine optimization" isimli bir yöntem uygulamıştır. Sistemin benzetim çalışmalarındaki performans sonuçları diğer MPPT yöntemleri ve devre şemaları ile karşılaştırılmıştır.

Karimi ve arkadaşları [16] PV ve bataryalardan oluşan mikro şebeke için merkezsiz bir güç yönetimi ve yük paylaşımı yöntemi önermiştir. Önerilen yöntemin farklı yük, PV üretimi ve akü şarj durumları için performansı yapılan deneyler ile test edilip gösterilmiştir. Badawy ve Sozer [17] $\mathrm{PV} / a k u ̈$ tabanlı elektrikli araç şarj istasyonunun güç akışı yönetimi için bir yöntem önermiştir. Bu yöntem ile PV/akü sistemlerinin şebeke ile entegrasyonunun artırılmasının ve artan elektrikli araç şarj talebinin karşılanmasının hedeflendiği belirtilmiştir. Mao ve arkadaşları [18] kısmi gölgelenme durumlarındaki PV sistemler için PSO ve $\mathrm{P} \& \mathrm{O}$ algoritmalarına dayanan özgün bir algoritma önermiştir. Önerilen algoritmanın performansı simülasyon ve deneysel çalışma ile test edilip sonuçları sunulmuştur.

\section{3. ÖNERILEN MODELLENMESI}

\subsection{PV Sistemin Modellenmesi}

PV hücreler için en çok kullanılan eşdeğer devre modeli Şekil 3'de gösterilen tek diyotlu eşdeğer devre modelidir.

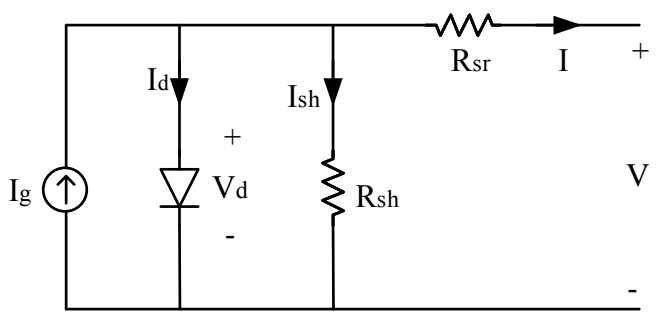

Şekil 3. PV hücrenin eşdeğer devresi [19]

Bu modelde PV hücre bir akım kaynağı buna paralel bağlanan bir diyot, direnç ve seri bağlanan bir direnç ile gösterilir. Bu devreye Kirchhoff'un akım yasası uygulandığında:

$\mathrm{I}=\mathrm{I}_{\mathrm{g}}-\mathrm{I}_{\mathrm{d}}-\mathrm{I}_{\mathrm{sh}}$

$I_{\mathrm{g}}$ hücreye düşen 1şık sonucu üretilen akımı gösterir. Hücreye düşen 1 şık şiddetine ve hücre sıcaklığına bağlı olarak değişmektedir. $\mathrm{I}_{\mathrm{d}}$ paralel kolda yer alan ve PV hücrenin lineer olmayan I-V karakteristiğini modelleyen diyot akımını gösterir. $I_{\text {sh }}$ paralel kolda yer alan direnç üzerinden geçen akımı gösterir. Diyot akımı $I_{d}$ ve paralel kol akımı $\mathrm{I}_{\text {sh }}$ yerine ilgili denklemler yazıldığında Eşitlik 2 elde edilir.

$\mathrm{I}=\mathrm{I}_{\mathrm{g}}-\mathrm{I}_{0}\left[\exp \left(\frac{\mathrm{V}+\mathrm{IR} \mathrm{sr}_{\mathrm{sr}}}{\mathrm{nkT} / \mathrm{q}}\right)-1\right]-\left(\frac{\mathrm{V}+\mathrm{IR}}{\mathrm{R}_{\mathrm{sh}}}\right)$

Hücre sıcaklığı ve 1şık şiddetinin bir fonksiyonu olan $\mathrm{I}_{\mathrm{g}}$ Eşitlik 3 'te ifade edilmiştir.

$\mathrm{I}_{\mathrm{g}}=\mathrm{I}_{\mathrm{scR}} \frac{\mathrm{G}}{\mathrm{G}_{\mathrm{R}}}\left[1+\propto_{\mathrm{T}}\left(\mathrm{T}_{\mathrm{c}}-\mathrm{T}_{\mathrm{cR}}\right)\right]$

$\mathrm{I}_{\text {scR }}$ referans 1 şı şiddeti $\left(G_{R}\right)$ ve sicaklık $\left(T_{c R}\right)$ değerlerinde hücrenin kısa devre akımını, $\propto_{\mathrm{T}}$ ise sicaklık sabitini ifade eder.

Eşitlik 2'de yer alan $\mathrm{I}_{0}$ ise doyma akımını ifade eder ve Eşitlik 4'deki gibi gösterilir.

$\mathrm{I}_{0}=\mathrm{I}_{0 \mathrm{R}}\left(\frac{\tau_{\mathrm{c}}}{\tau_{\mathrm{cR}}}\right) \exp \left[\left(\frac{1}{\tau_{\mathrm{cR}}}-\frac{1}{\tau_{\mathrm{c}}}\right) \frac{\mathrm{q} \epsilon_{\mathrm{g}}}{\mathrm{nk}}\right]$

Eşitlik 2 ve Eşitlik 4'de yer alan diğer parametrelerden q elektron yükünü, k Boltzmann sabitini, $\epsilon_{g}$ boşluk (band-gap) enerjisini, n diyot idealite faktörünü ifade eder. [18] 
PV sistem Çizelge 1'de özellikleri belirtilen paneller kullanılarak 22 seri,250 paralel bağlantı olacak şekilde oluşturulmuştur. Oluşturulan PV dizinin nominal çıkış gücü 300 kVA olarak hesaplanmıştır.

Çizelge 1. PV panelin parametreleri

\begin{tabular}{|l|c|}
\hline Parametre & Değer \\
\hline Hücre Etkin Alanı $\left(\mathrm{m}^{2}\right)$ & 0,01 \\
\hline Hücre Seri Direnci $\left(\mathrm{R}_{\mathrm{sr}}\right)$ & 0,02 \\
\hline Hücre Şönt Direnci $\left(\mathrm{R}_{\mathrm{sh}}\right)$ & 100 \\
\hline Diyot idealite faktörü $(\mathrm{n})$ & 1,5 \\
\hline Hücre Doyma Akımı $(\mathrm{kA})$ & $1 \mathrm{e}^{-12}$ \\
\hline Hücre K1sa Devre Akımı $(\mathrm{kA})$ & 0,0025 \\
\hline Sicaklık Sabiti $\left(\propto_{\mathrm{T}}\right)$ & 0,001 \\
\hline
\end{tabular}

\subsection{Akü Sisteminin Modellenmesi}

Elektrokimyasal tekrar şarj edilebilir aküler enerjiyi kolaylıkla depolayıp gerektiğinde kullanıma sunma özellikleri nedeni ile güç sistemlerinde yaygın bir kullanım alanı bulmuştur. Bu akülerin birçok tipi olmakla birlikte, bunların performans analizi için birçok farklı matematiksel model mevcuttur. Şekil 1'de gerilim kaynağının bir dirence seri bağlanması ile oluşturulan model gösterilmiştir [20].

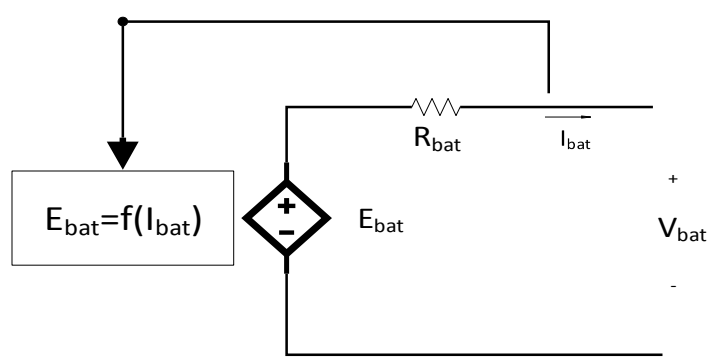

Şekil 4. Akünün eşdeğer devresi [19]

Belirli zaman aralıklarıyla gerilim kaynağının gerilim değeri bataryanın şarj seviyesi kullanılarak hesaplanır. Şekil 4'de yüksüz durumdaki akü geriliminin akünün şarj değeri kullanılarak hesaplanması gösterilmiştir.

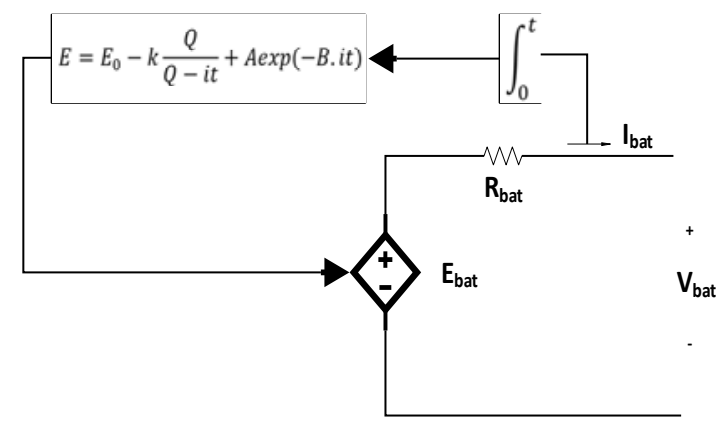

Şekil 5. Lineer olmayan akü modeli

Şekil 5'deki parametrelerden E yüksüz durumda akü gerilimini (V), $\mathrm{E}_{0}$ sabit akü gerilimini (V), K polarizasyon gerilimini (K), Q akü kapasitesini (Ah), $\int i d t$ ise anlık akü şarj durumunu ifade etmektedir. Akü gerilimi akü şarj seviyesi cinsinden ifade edilmek üzere Eşitlik 5'deki gibi düzenlenebilir.

$\mathrm{E}=\mathrm{E}_{0}-\mathrm{K} \frac{1}{\mathrm{SOC}}+\mathrm{Ae} \mathrm{e}^{-\mathrm{B} \cdot \mathrm{Q} \cdot(1-\mathrm{SOC})}$

Önerilen sistemde kullanılan akünün parametreleri Çizelge 2'de verilmiştir.

Çizelge 2. Akünün parametreleri

\begin{tabular}{|l|c|}
\hline Parametre & Değer \\
\hline Nominal Gerilim (kV) & 0,5 \\
\hline Nominal Kapasite (kAh) & 0,00658 \\
\hline Nominal Kapasite (pu) & 0,95 \\
\hline Rezistif Gerilim Düşümü (pu) & 0,05 \\
\hline Üstel Noktadaki Gerilim (pu) & 1,03 \\
\hline Üstel Noktadaki Kapasite (pu) & 0,4 \\
\hline Tam Şarj Gerilimi (pu) & 1,15 \\
\hline
\end{tabular}

\subsection{Yükün Modellenmesi}

Önerilen sistemde doğrusal yük, ihtiyaç duyulan aktif güç değerine göre Şekil 6'da gösterilen formül ile yük direnci ayarlanarak kullanılmıştır. Benzetim çalışmaları sırasında $\mathrm{P}_{\text {yük }} 0$ ila $500 \mathrm{~kW}$ arasında değişecek şekilde $\mathrm{R}_{\text {yük }}$ değeri ayarlanarak kontrol edilmiştir. 


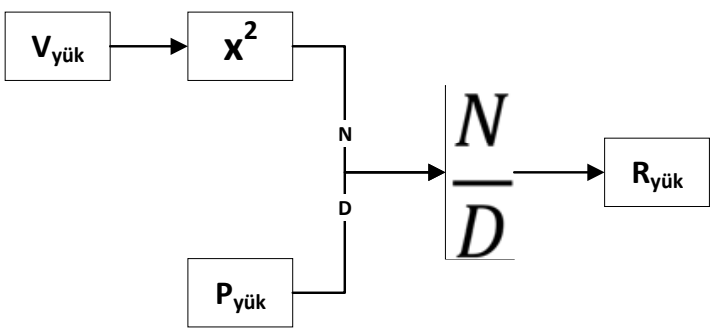

Şekil 6. Yük gerilimi ve gücü kullanılarak rezistif direncin hesaplanması

\section{4. ÖNERILLEN KONTROLÜ}

Bu bölümde Sekil 7'de şeması görülen, önerilen sistemdeki PV ve akü sistemlerinin kontrolü anlatılacaktır.

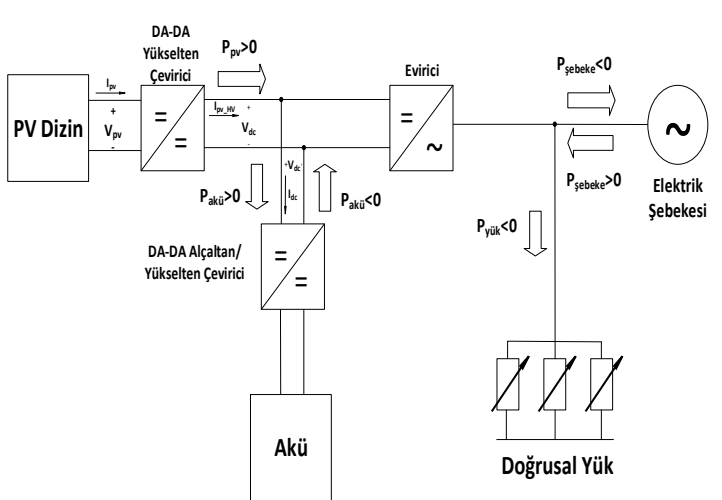

Şekil 7. Önerilen sistemin şeması

\subsection{PV Sistemin Kontrolü}

PV sistemlerde üretilen güç yük talebi ile uyuşmadığında verim kaybı ortaya çıkmaktadır. Bu sorunu önlemek için PV sistemin maksimum güç noktasında çalıştırılması gerekir. Panel sıcaklığı ve ışınım yoğunluğundaki değişiklikler maksimum güç noktasını etkilemektedir. PV sistemin çalışma noktasından kaynaklanan kayıpları önlemek için bir maksimum güç noktası izleyicisinin kullanılması önem arz etmektedir. Önerilen sistemde maksimum güç noktası takibi için $\mathrm{P} \& \mathrm{O}$ algoritması kullanılmıştır. Algoritmanın amacı PV sistemin maksimum güç ürettiği $V_{\text {mpp }}$ ve $I_{m p p}$ noktalarını tespit ederek sistemin bu noktada çalışmasını sağlamaktır. Belirli aralıklar ile PV sistemin gerilim değerinin ayarlanması sonrası sistem çıkış gücü kontrol edilir. Çıkış gücünün durumuna göre bir sonraki adımda gerilim değerinin artırılacağına veya azaltılacağına karar verilir. Şekil 8'de P\&O algoritmasının akış diyagramı gösterilmiştir.

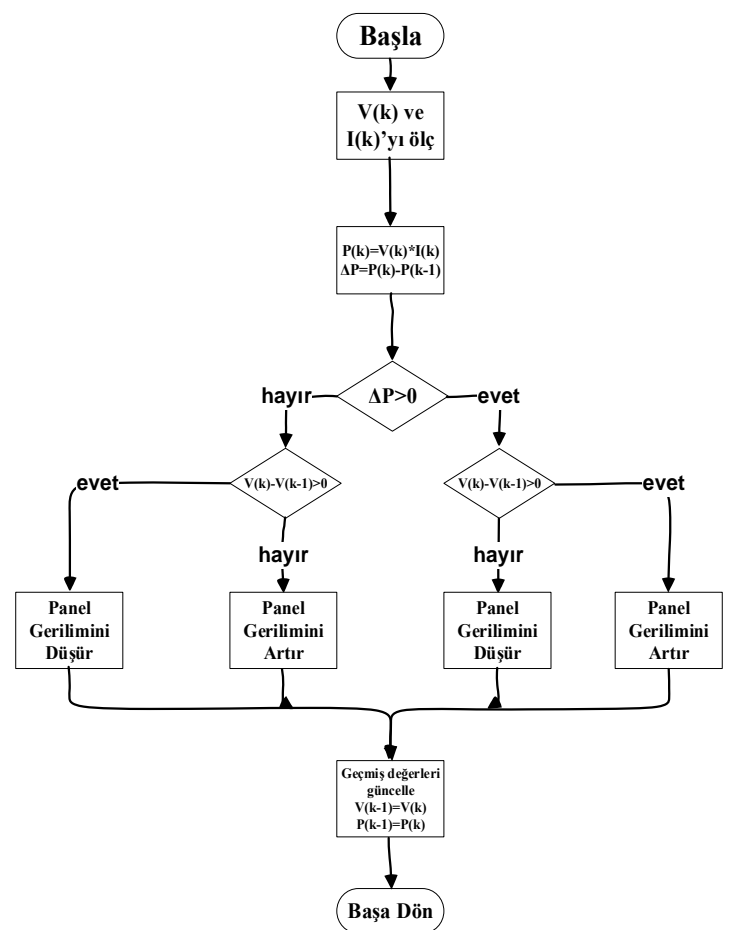

Şekil 8. $P \& O$ algoritmasının akış diyagramı

MPPT algoritması tarafindan üretilen referans gerilim değeri Şekil 9'da görülen Yükselten çevirici tarafından DA bara akımını $\left(\mathrm{I}_{\mathrm{pv}} \mathrm{HV}\right)$ ayarlamak için kullanılır. DA bara gerilimi ise Şekil 10'da gösterilen evirici tarafından ayarlanır.

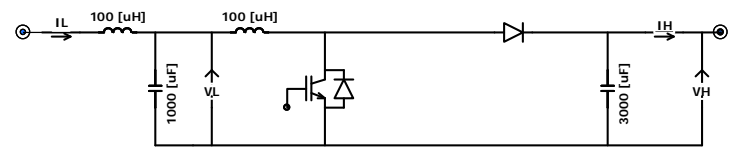

Şekil 9. Yükselten çevirici devre şeması

Yükselten çeviricinin kontrol şeması Şekil 10'da gösterilmiş̧ir. Bu şemada Plim önceden tanımlanan maksimum güç değerini, $\mathrm{VH}$ ve IH sirasiyla yükselten çeviricinin yüksek gerilim tarafında ölçülen gerilim ve akım değerlerini ifade eder. $\mathrm{Bu}$ 
değerler kullanılarak hesaplanan güç değeri PI kontrol sistemine geri besleme sinyali olarak gönderilir. Kontrol sistemi yükselten çevirici içerisinde yer alan IGBT'nin tetikleme sinyalini kontrol eder. Ayrıca referans güç değerinin maksimum güç değeri ile karşılaştırılması sonucu oluşturulan EnableBoost sinyali ile sadece referans güç değerinin maksimum güç değerinden küçük olduğu durumlarda çeviricinin çalışması sağlanmıştır.

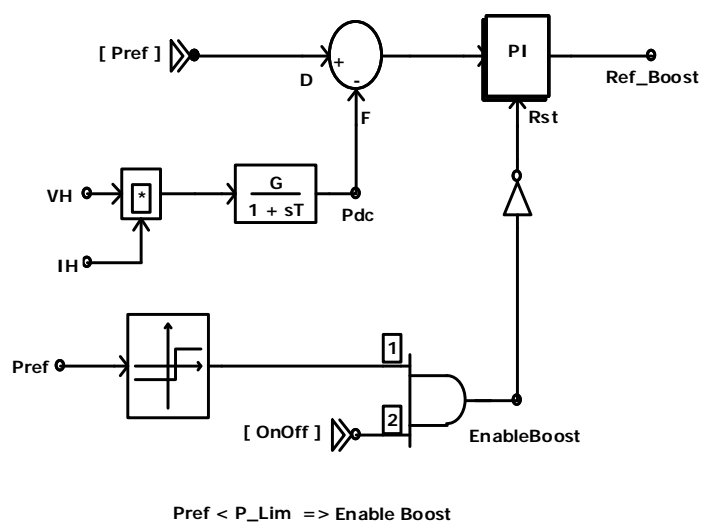

Şekil 10. Yükselten çevirici kontrol şeması

DA bara gerilimi Şekil 11'de devre şeması ve Şekil 12'de kontrol şeması gösterilen evirici tarafindan ayarlanır. Şekil 12'de Edc ve Edc_ref parametreleri sırasıyla DA gerilim ve DA Referans gerilim parametrelerini ifade eder. Panel sıcaklığ veya ışınım yoğunluğu parametrelerinden birinde değişiklik olduğu zaman PV sistemin çıkış gücü değişmektedir. Yükselten çevirici bu değişiklik sonucu akım artırmak veya azaltmak için duty cycle değerini değiştirir.

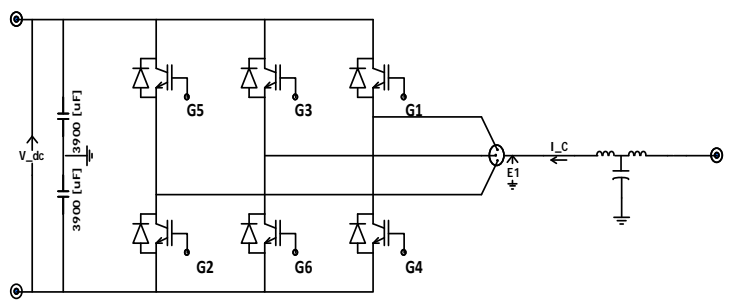

Şekil 11. Evirici devre şeması

Bunun sonucunda DA bara gerilimi de değişir. DA bara gerilimini eski haline getirmek amaciyla evirici DA baradan talep ettiği akımı artırma veya azaltma yoluna gider. Böylece DA bara geriliminin kontrolü sağlanmış olur.

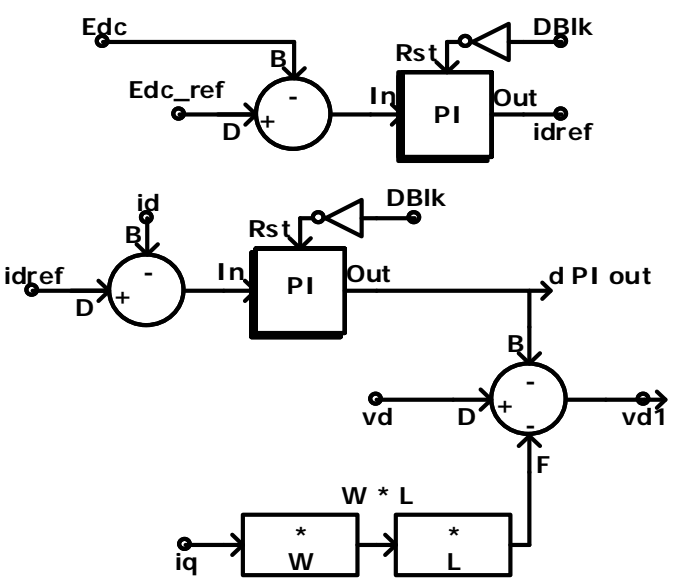

Şekil 12. Evirici DA gerilim kontrolü şeması

\subsection{Akü Sisteminin Kontrolü}

Akü Şekil 13'de devre şeması gösterilen alçaltan/yükselten çevirici aracılığı ile DA baraya bağlanır. Alçak gerilim (200V) tarafı aküye, yüksek gerilim $(250 \mathrm{~V})$ tarafi DA baraya bağlıdır.

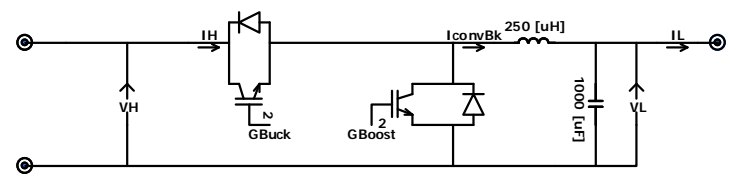

Şekil 13. Alçaltan/yükselten çevirici devre şeması

Şarj kontrolcüsünün açık veya kapalı olması, açık olduğu durumda şarj veya deşarj modunda çalışmasının kontrolü Şekil 14'de gösterilmiştir. Bu şemada ChargerState kontrolcünün açık veya kapalı olma durumunu, SOC akülerin şarj yüzdesini, mode ise kontrolcünün şarj veya deşarj durumunu ifade eder.

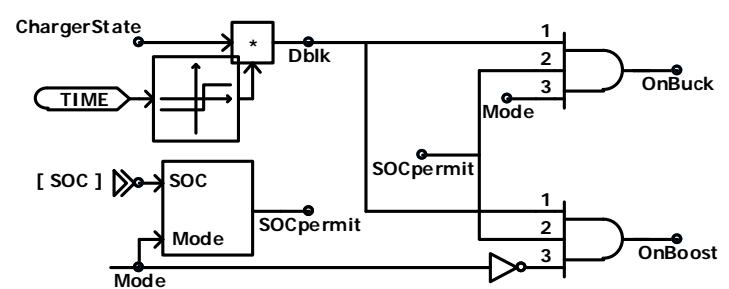

Şekil 14. Akü sistemi üst seviye kontrol şeması 
Doğrusal Yükleri Besleyen Şebeke Bağlantılı PV/Akü Sisteminin Tasarımı ve Tam/Kısmi Gölgelenme Durumlarında Performans Analizi

ChargerState ve Mode parametreleri Şekil $15^{\prime}$ de gösterilen akış diyagramına göre kontrol edilir.

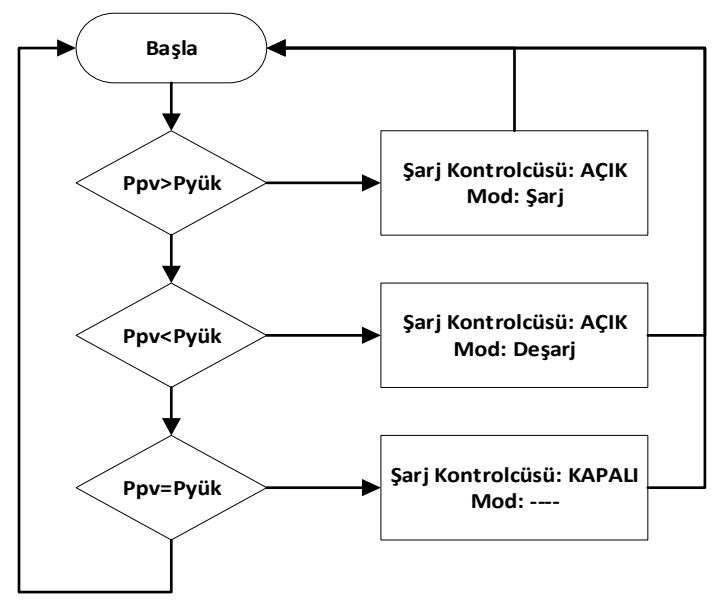

Şekil 15. Akü sistemi kontrolü akış diyagramı

Alçaltan/yükselten çevirici şarj modunda çalıştığı zaman alçaltan modu (Buck mode) devrededir. Alçaltan çeviricinin şarj kontrolcüsü Şekil 16'da gösterilmiştir.

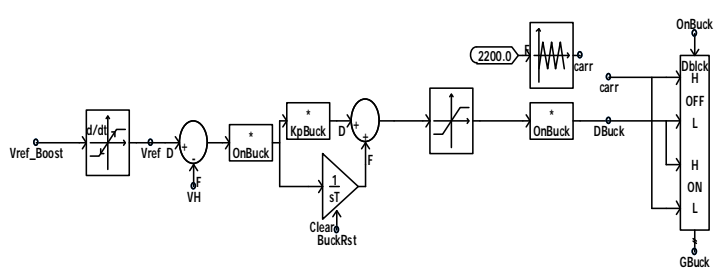

Şekil 16. Alçaltan modu şarj kontrolcüsü

Alçaltan çeviricinin sisteme zarar verecek akımlara çıkmasını engellemek amacı ile duty cycle değeri Şekil 17'de gösterildiği gibi sınırlandırılmıştır.

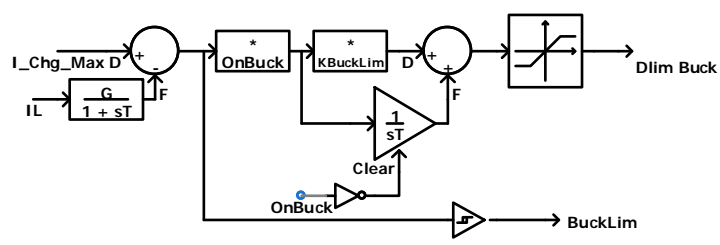

Şekil 17. Alçaltan modunda yüksek akımlara karşı duty cycle değerinin sinırlanması

Çevirici deşarj modunda çalıştığı zaman yükselten modu (Boost mode) devrededir. Yükselten modunun şarj kontrolcüsü şekil 18 'de gösterilmiştir.

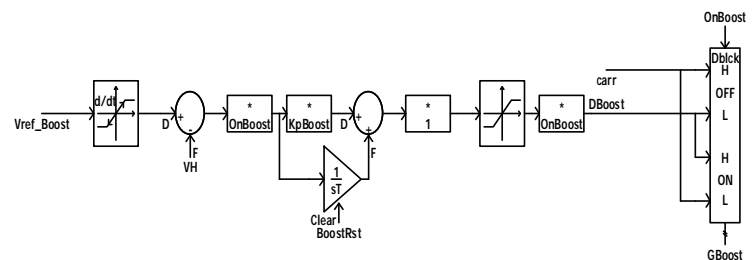

Şekil 18. Yükselten modu şarj kontrolcüsü

Yükselten çeviricinin sisteme zarar verecek akımlara çıkmasını engellemek amacı ile çeviricinin duty cycle değeri Şekil 19'da gösterildiği gibi sınırlandırılmıştır.

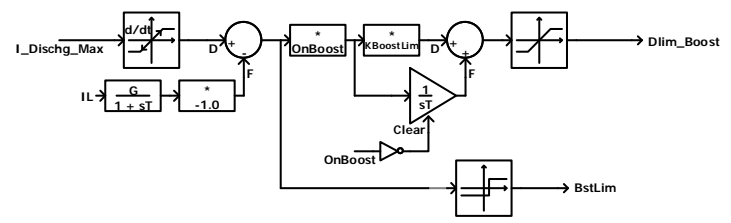

Şekil 19. Yükselten modunda yüksek akımlara karşı duty cycle değerinin sınırlanması

\section{BENZETIMM SONUCCLARI}

ÇALIŞMASI

$\mathrm{Bu}$ bölümde önerilen sistemin farklı 1şınım yoğunluğu, gölgelenme ve sicaklık parametrelerine göre performansı 6 farklı senaryo üzerinden incelenecektir. Şekil 7'de güç akışı yönlerine göre işaretler belirtilmiştir. Çizelge 3'de ise yük devreye girdikten sonraki güç değerlerine göre senaryoların özeti verilmiştir.

Çizelge 3. Benzetim çalışması senaryo özeti

\begin{tabular}{|c|c|c|c|c|c|}
\hline No. & $\begin{array}{c}\text { Gölgelenme } \\
\text { Durumu }\end{array}$ & PV & Akü & Yük & $\begin{array}{c}\text { Elektrik } \\
\text { Şebekesi }\end{array}$ \\
\hline 1 & Yok & $300 \mathrm{~kW}$ & $0 \mathrm{~kW}$ & {$[-300] \mathrm{kW}$} & $0 \mathrm{~kW}$ \\
\hline 2 & Yok & $300 \mathrm{~kW}$ & $\begin{array}{c}{[0,5]} \\
\mathrm{kW}\end{array}$ & $\begin{array}{c}{[-300,-} \\
200] \mathrm{kW}\end{array}$ & $\begin{array}{c}{[-100,0]} \\
\mathrm{kW}\end{array}$ \\
\hline 3 & $\begin{array}{c}\% 100[300, \\
1000] \mathrm{W} / \mathrm{m}^{2}\end{array}$ & $\begin{array}{c}{[50,300]} \\
\mathrm{kW}\end{array}$ & $\begin{array}{c}{[-15,5]} \\
\mathrm{kW}\end{array}$ & {$[-300] \mathrm{kW}$} & $\begin{array}{c}{[-50,150]} \\
\mathrm{kW}\end{array}$ \\
\hline 4 & $\begin{array}{c}\% 100[300, \\
1000] \mathrm{W} / \mathrm{m}^{2}\end{array}$ & $\begin{array}{c}50,300] \\
\mathrm{kW}\end{array}$ & $\begin{array}{c}{[-15,5]} \\
\mathrm{kW}\end{array}$ & $\begin{array}{c}{[-350,-250]} \\
\mathrm{kW}\end{array}$ & $\begin{array}{c}{[-50,150]} \\
\mathrm{kW}\end{array}$ \\
\hline 5 & $\begin{array}{c}\% 25[300, \\
1000] \mathrm{W} / \mathrm{m}^{2}\end{array}$ & $\begin{array}{c}{[150,300]} \\
\mathrm{kW}\end{array}$ & $\begin{array}{c}{[-15,5]} \\
\mathrm{kW}\end{array}$ & {$[-300] \mathrm{kW}$} & $\begin{array}{c}{[-50,100]} \\
\mathrm{kW}\end{array}$ \\
\hline 6 & $\begin{array}{c}\% 25[300, \\
1000] \mathrm{W} / \mathrm{m}^{2}\end{array}$ & $\begin{array}{c}{[150,300]} \\
\mathrm{kW}\end{array}$ & $\begin{array}{c}{[-15,5]} \\
\mathrm{kW}\end{array}$ & $\begin{array}{c}{[-400,-300]} \\
\mathrm{kW}\end{array}$ & $\begin{array}{c}{[-50,300]} \\
\mathrm{kW}\end{array}$ \\
\hline
\end{tabular}




\subsection{Senaryo 1}

$\mathrm{Bu}$ senaryoda PV dizin $1000 \mathrm{~W} / \mathrm{m}^{2} \quad$ 1şınım

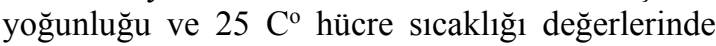
çalışmakta ve PV dizin tarafından üretilen güç yük talebini tam olarak karşılamaktadır. Dolayısı ile akünün şarj kontrolcüsü kapalı konumdadır.

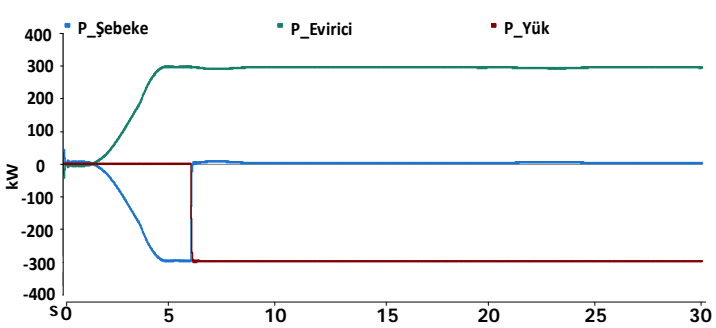

Şekil 20. Önerilen sistemin aktif güç grafiği

\subsection{Senaryo 2}

$\mathrm{Bu}$ senaryoda PV dizin $1000 \mathrm{~W} / \mathrm{m}^{2} \quad$ 1şınım yoğunluğu ve $25 \mathrm{C}^{\circ}$ hücre sicaklığı değerlerinde çalışmakta ve üretilen gücün yük talebinden az ve eşit olduğu durumların sonuçları gözlenebilmektedir. Şekil 21'de 6 ila 15. saniyeler arasında yük talebi PV dizinin ürettiği güçten az olduğu için akünün şarj olduğu ve elektrik şebekesine güç aktarımı olduğu görülmektedir. 16. saniyeden sonra yük talebi PV dizin tarafindan üretilen güce ulaştığı için akü ve elektrik şebekesine güç aktarımının durduğu görülmektedir.

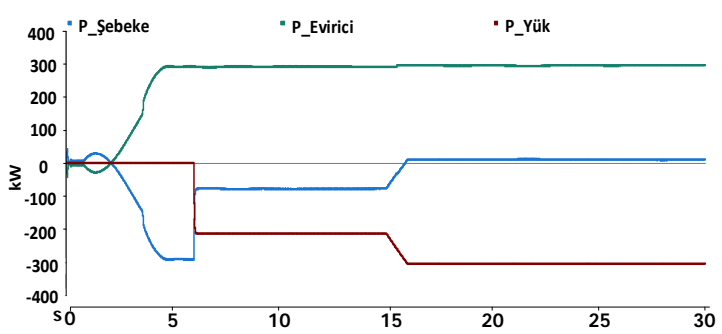

Şekil 21. Önerilen sistemin aktif güç grafiği

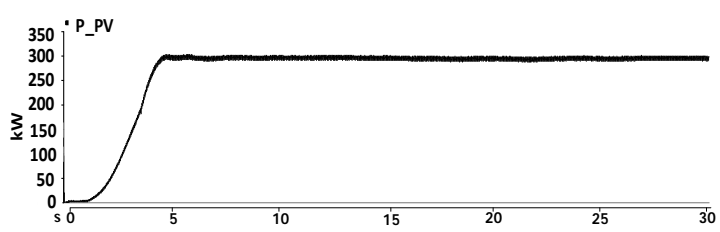

Şekil 22. PV dizinin aktif güç grafiği

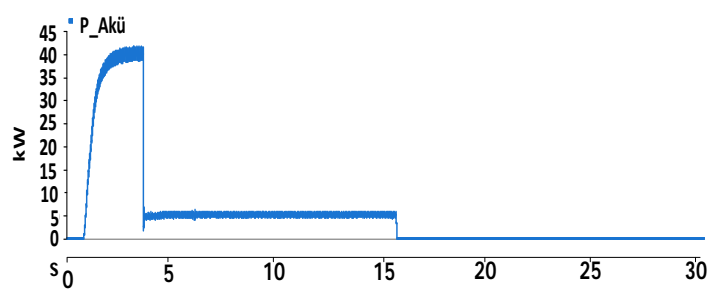

Şekil 23. Akünün aktif güç grafiği

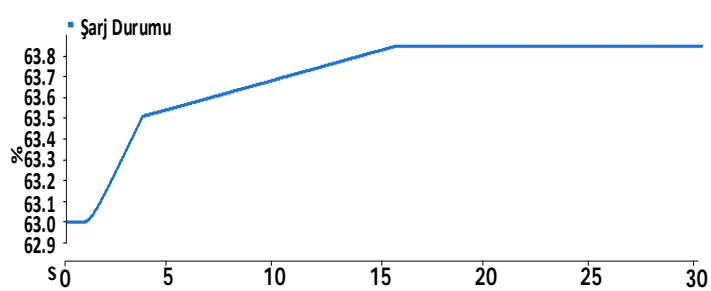

Şekil 24. Akünün şarj durumu grafiği

\subsection{Senaryo 3}

Bu senaryoda PV dizinin üç farklı 1şınım yoğunluğu ve sıcaklık seviyesinde çalışması sonucu akünün deşarj olmaya başlayarak yükü beslemesi görülmektedir. Şekil 25'de 10. ve 20. saniyelerde 1şınım yoğunluğu ve sicaklık değerlerinin değişmesi sonucunda akünün deşarj olmaya başlaması, akünün gücünün yük talebine yetmemesi sonucu elektrik şebekesinden de yüke bir güç akışı olduğu gözlenebilmektedir.

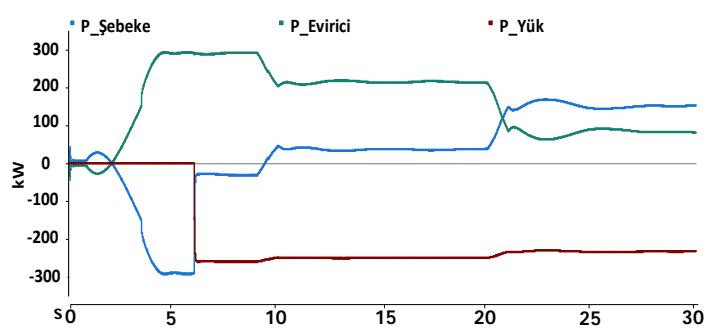

Şekil 25. Önerilen sistemin aktif güç grafiği

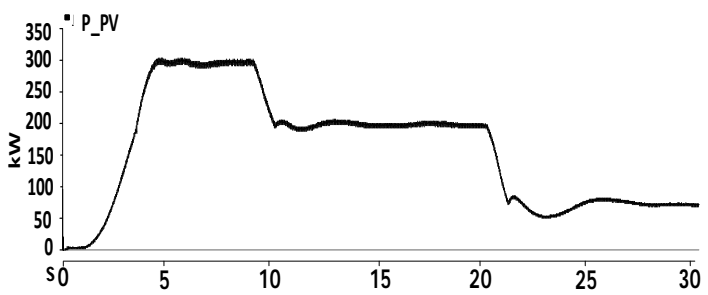

Şekil 26. PV dizinin aktif güç grafiği 
Doğrusal Yükleri Besleyen Şebeke Băglantılı PV/Akü Sisteminin Tasarımı ve Tam/Kısmi Gölgelenme Durumlarında Performans Analizi

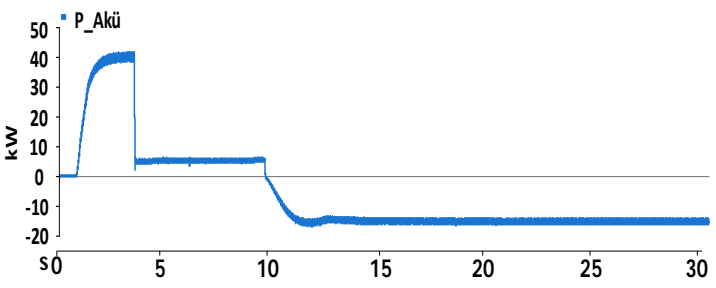

Şekil 27. Akünün aktif güç grafiği

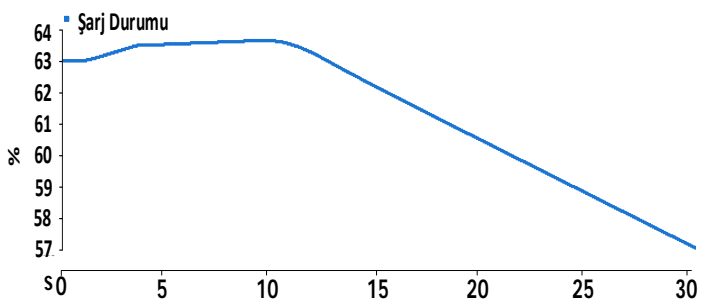

Şekil 28. Akünün şarj durumu grafiği

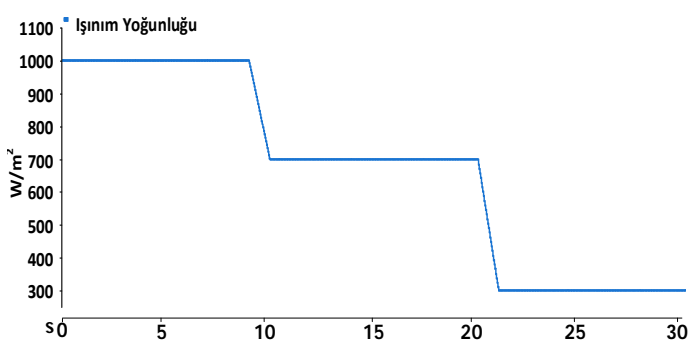

Şekil 29. Işınım yoğunluğu grafiği

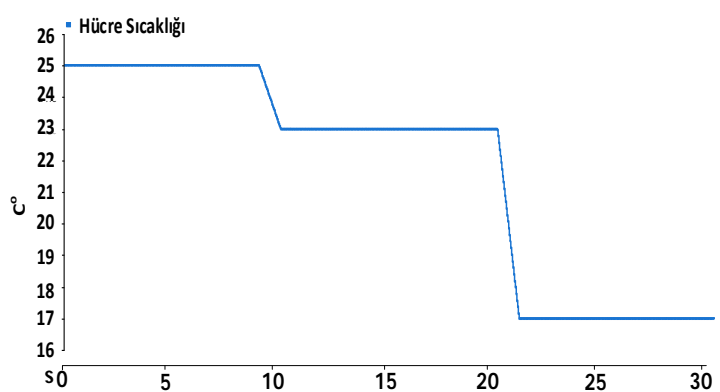

Şekil 30. Hücre sıcaklı̆̆ grafiği

\subsection{Senaryo 4}

$\mathrm{Bu}$ senaryoda senaryo 3'de olduğu gibi 1şınım yoğunluğu ve sıcaklık değerlerinin değişmesi sonucu PV dizin çıkış gücünün azalması ile akünün yükü beslemek üzere deşarj olmaya başlaması ve elektrik şebekesinden yüke güç akışı olduğu görülmektedir. Yük talebi senaryo 3'e göre daha fazla arttığı için elektrik şebekesinden aktarılan gücün arttığı da görülmektedir.

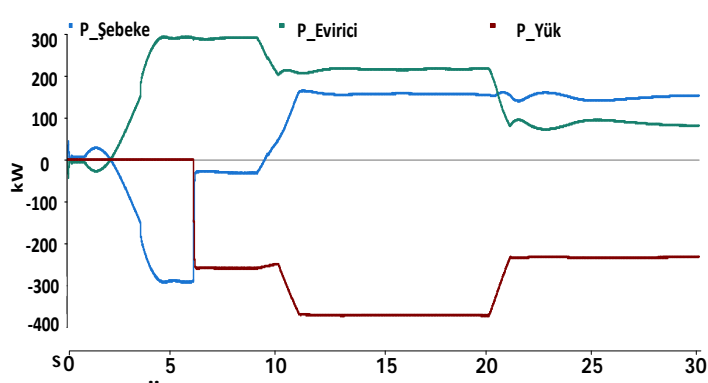

Şekil 31. Önerilen sistemin aktif güç grafiği

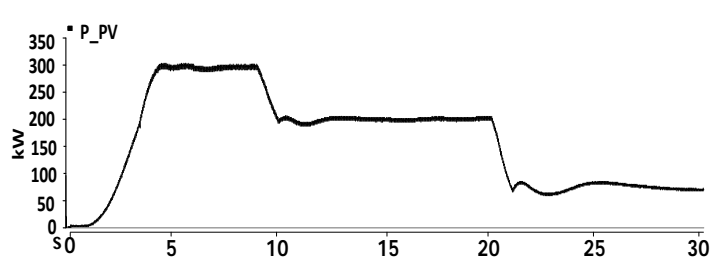

Şekil 32. PV dizinin aktif güç grafiği

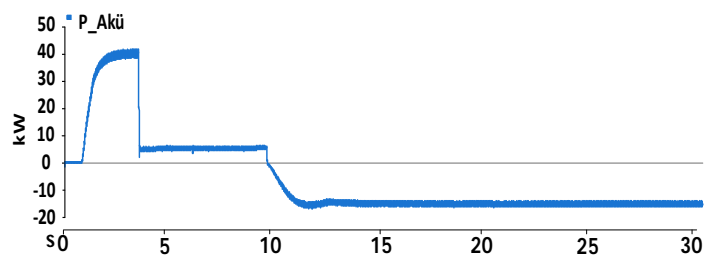

Şekil 33. Akünün aktif güç grafiği

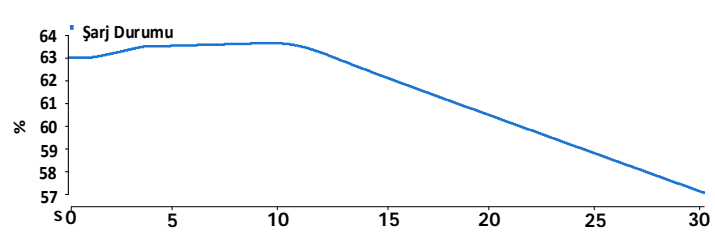

Şekil 34. Akünün şarj durumu grafiği

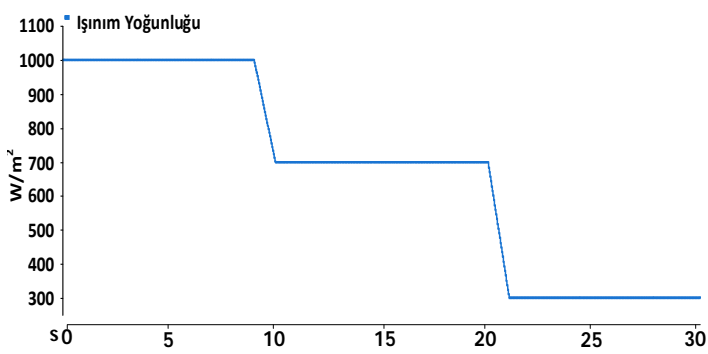

Şekil 35. Işınım yoğunluğu grafiğgi 


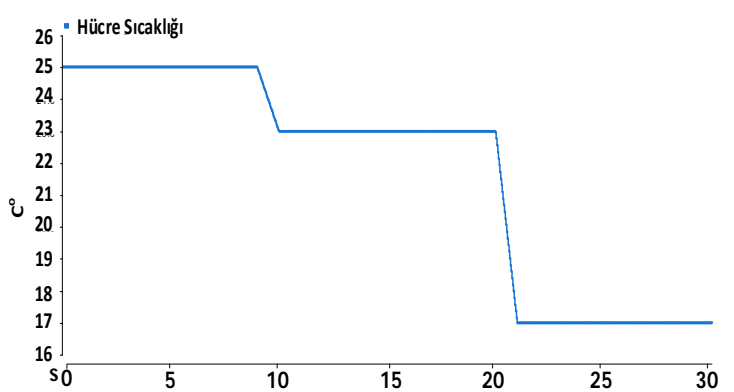

Şekil 36. Hücre sıcaklığı grafiği

\subsection{Senaryo 5}

$\mathrm{Bu}$ senaryoda $\mathrm{PV}$ dizindeki panellerin $\% 75^{\prime} \mathrm{i}$ $1000 \mathrm{w} / \mathrm{m}^{2}$ 1şınım yoğunluğu ve $25{ }^{\circ} \mathrm{C}$ sicaklık değerlerinde çalışırken \%25'i için 1şınım yoğunluğu ve sıcaklık değişimi Şekil 41 ve 42 'de gösterilmiştir. 10. saniye'ye kadar PV dizinin ürettiği güç yük talebinden fazla olduğu için akünün şarj olduğu ve elektrik şebekesine güç aktarıldı̆̆ görülürken, 10. saniye'de dizindeki panellerin \%25'inin gölgelenmesi $\left(700 \mathrm{~W} / \mathrm{m}^{2}\right)$ ile PV dizinin ç1kış gücü düşmüş bunun sonucunda akü deşarj olmaya başlamıştır. 20. saniye'de gölgelenmenin artması ile $\left(300 \mathrm{~W} / \mathrm{m}^{2}\right)$ dizinin çıkış gücü daha fazla düşmüş ve elektrik şebekesinden çekilen güç artmıştır.

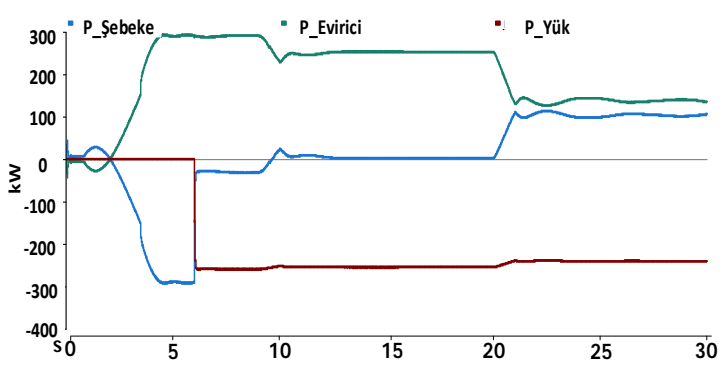

Şekil 37. Önerilen sistemin aktif güç grafiği

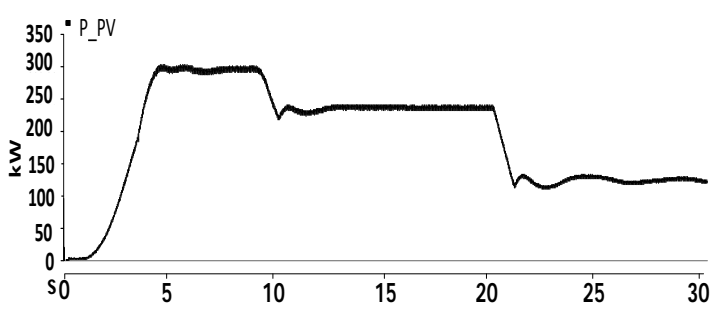

Şekil 38. PV dizinin aktif güç grafiği

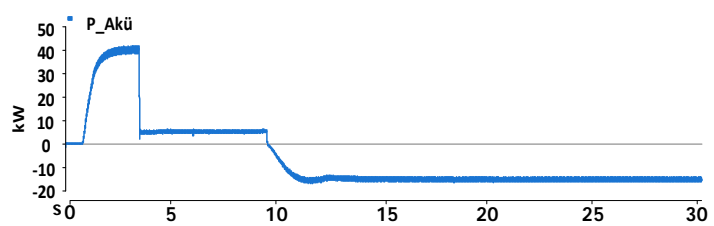

Şekil 39. Akünün aktif güç grafiği

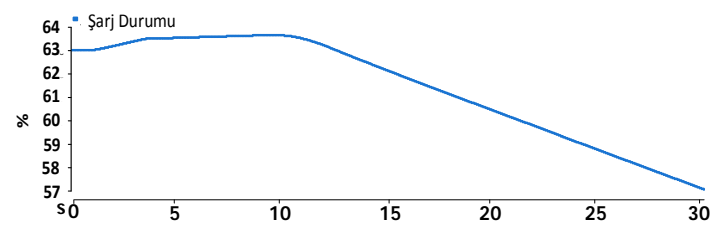

Şekil 40. Akünün şarj durumu grafiği

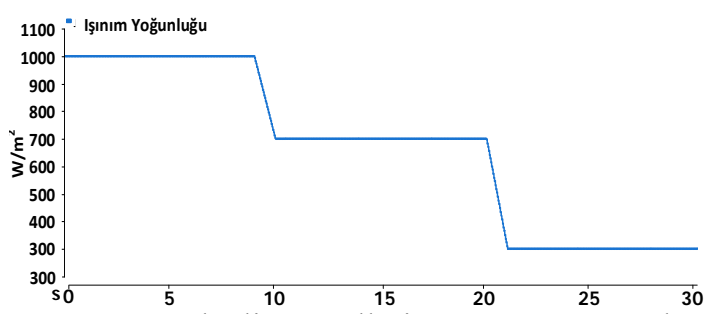

Şekil 41. Gölgeli panellerin 1şınım yoğunluğu grafiği

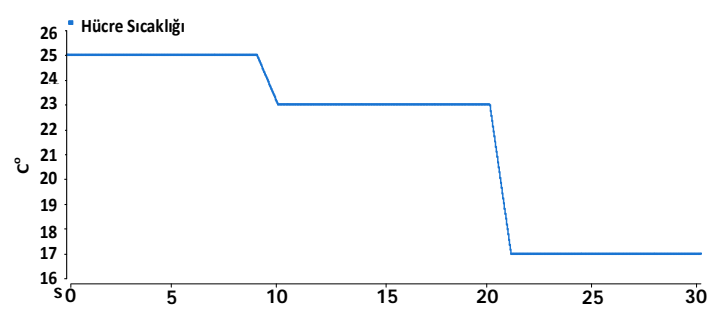

Şekil 42. Gölgeli panellerin hücre sıcaklığı grafiği

\subsection{Senaryo 6}

$\mathrm{Bu}$ senaryoda da senaryo 5'de olduğu gibi PV dizindeki panellerin \%75'i $1000 \mathrm{w} / \mathrm{m}^{2}$ 1şınım yoğunluğu ve $25 \mathrm{C}^{\circ}$ sıcaklık değerlerinde çalışırken \%25'i için 1şınım yoğunluğu ve sıcaklık değerleri şekil 46 ve 47'de verilmiştir. Senaryo 5'de olduğu gibi 10. ve 20. saniyelerde gölgeli hücrelerin ışınım yoğunluğu değerinin düşmesi sonucu PV dizinin çıkış gücünün düştüğü bunun sonucunda akünün deşarj olmaya başlayıp elektrik şebekesinden yüklere güç aktarıldığı görülmektedir. Senaryo 
Doğrusal Yükleri Besleyen Şebeke Băglantılı PV/Akü Sisteminin Tasarımı ve Tam/Kısmi Gölgelenme Durumlarında Performans Analizi

5'den farklı olarak yükün talebi de arttığı için elektrik şebekesinden talep edilen güç de artmıştır.

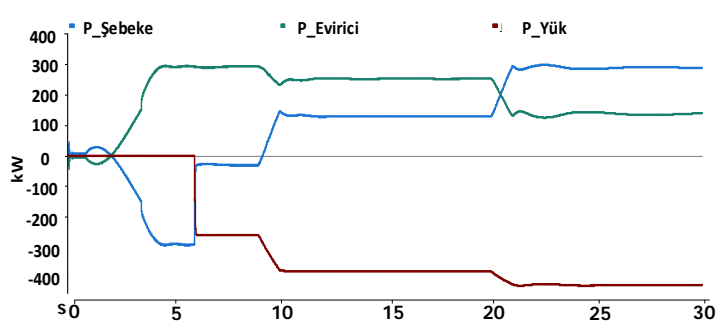

Şekil 43. Önerilen sistemin aktif güç grafiği

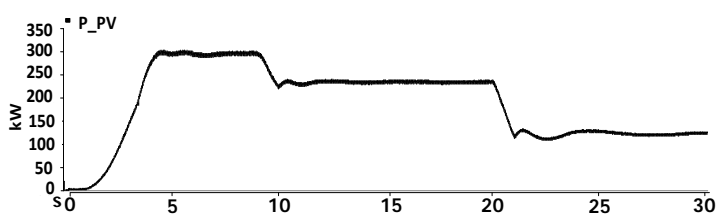

Şekil 44. PV dizinin aktif güç grafiğgi

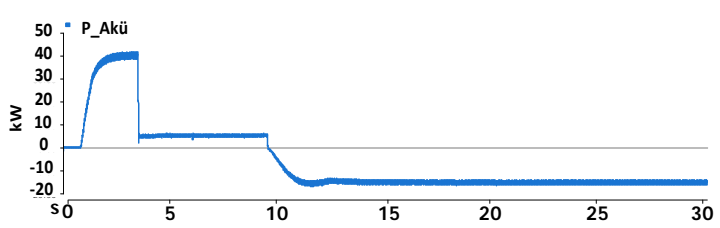

Şekil 45. Akünün aktif güç grafiği

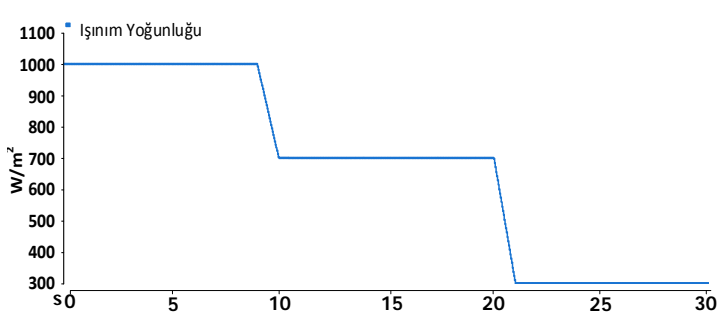

Şekil 46. Gölgeli panellerin ışınım yoğunluğu grafiği

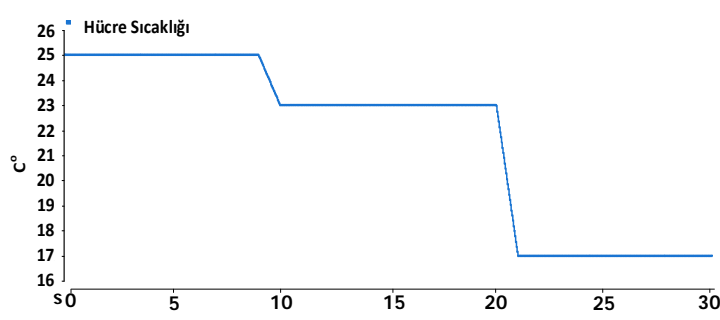

Şekil 47. Gölgeli panellerin hücre sıcaklığı grafiği

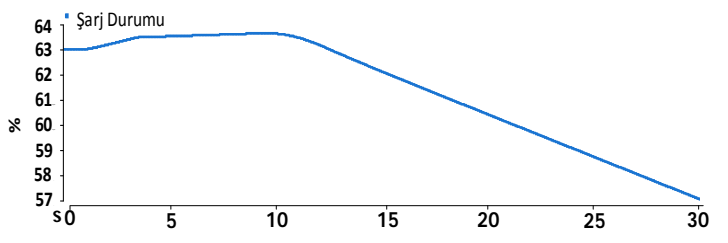

Şekil 48. Akünün şarj durumu grafiği

\subsection{Gölgelenme Durumlarında PV Sistemin Karakteristiği}

Şekil 49 ve $50 \mathrm{PV}$ dizinin $1000 \mathrm{~W} / \mathrm{m}^{2}$ ve $25^{\circ} \mathrm{C}$ 'de çalışırken I-V ve P-V grafiklerini göstermektedir.

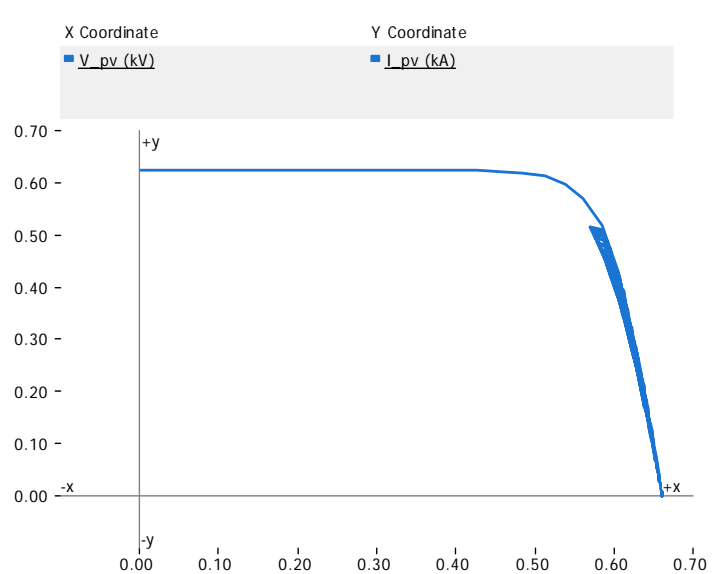

Şekil 49. PV dizinin I-V grafiği $\left(1000 \mathrm{~W} / \mathrm{m}^{2}\right.$ 1şınım yoğunluğu ve $25{ }^{\circ} \mathrm{C}$ hücre sicaklığında)
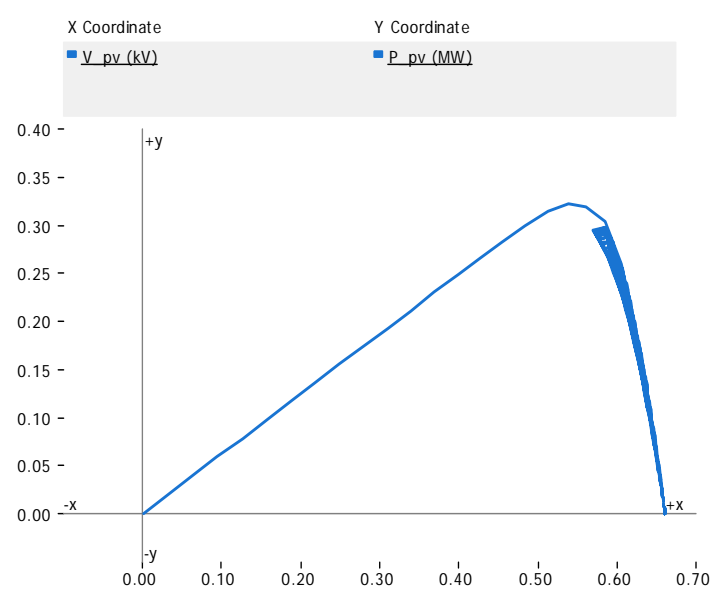

Şekil 50. PV dizinin P-V grafiği $\left(1000 \mathrm{~W} / \mathrm{m}^{2}\right.$ 1şııım yoğunluğu ve $25^{\circ} \mathrm{C}$ hücre sicaklığında) 
Şekil 51 ve $52 \mathrm{PV}$ dizinin $\% 75$ 'i $1000 \mathrm{~W} / \mathrm{m}^{2}$ ve $25 \mathrm{C}^{\circ}$ 'de, $\% 25$ ' $\mathrm{i} 700 \mathrm{~W} / \mathrm{m}^{2}$ ve $23 \mathrm{C}^{\circ}$ 'de çalışırken $\mathrm{I}-\mathrm{V}$ ve $\mathrm{P}-\mathrm{V}$ grafiklerini göstermektedir.

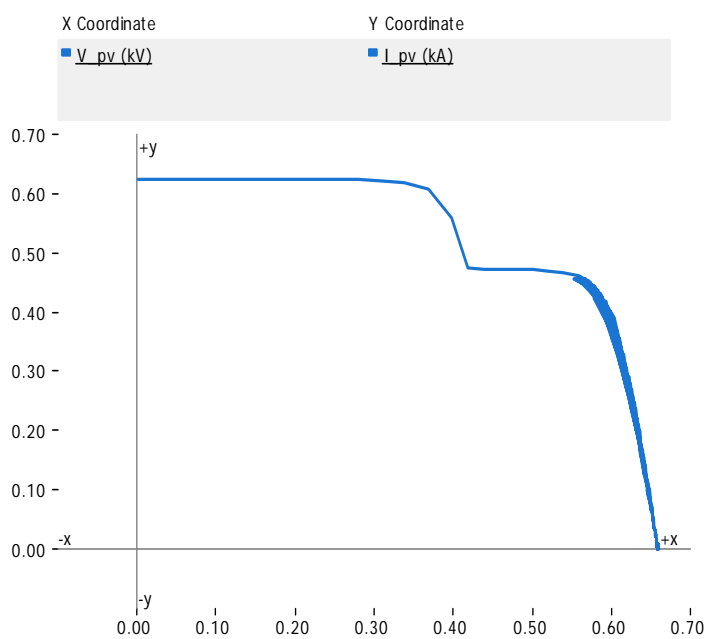

Şekil 51. PV dizinin I-V grafiği (\%75'i $1000 \mathrm{~W} / \mathrm{m}^{2}$ ve $25^{\circ} \mathrm{C}^{\prime} \mathrm{de} \% 25^{\prime}$ i $700 \mathrm{~W} / \mathrm{m}^{2}$ ve $23{ }^{\circ} \mathrm{C}^{\prime} \mathrm{de}$ )

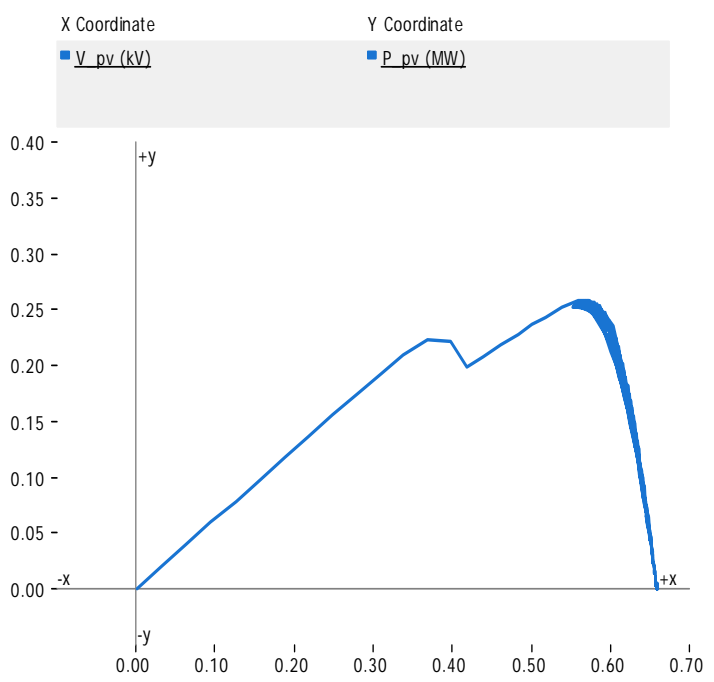

Sekil 52. PV dizinin P-V grafiği $(\% 75$ ' $1000 \mathrm{~W} / \mathrm{m}^{2}$ ve $25^{\circ} \mathrm{C}^{\prime} \mathrm{de} \% 25^{\prime} \mathrm{i} 700 \mathrm{~W} / \mathrm{m}^{2}$ ve $23{ }^{\circ} \mathrm{C}^{\prime} \mathrm{de}$ )

Şekil 51 ve $52 \mathrm{PV}$ dizinin $\% 75^{\prime} \mathrm{i} 1000 \mathrm{~W} / \mathrm{m}^{2}$ ve $25^{\circ} \mathrm{C}$ 'de, $\% 25^{\prime}$ i $300 \mathrm{~W} / \mathrm{m}^{2}$ ve $16{ }^{\circ} \mathrm{C}$ 'de çalışırken $\mathrm{I}-\mathrm{V}$ ve $\mathrm{P}-\mathrm{V}$ grafiklerini göstermektedir.
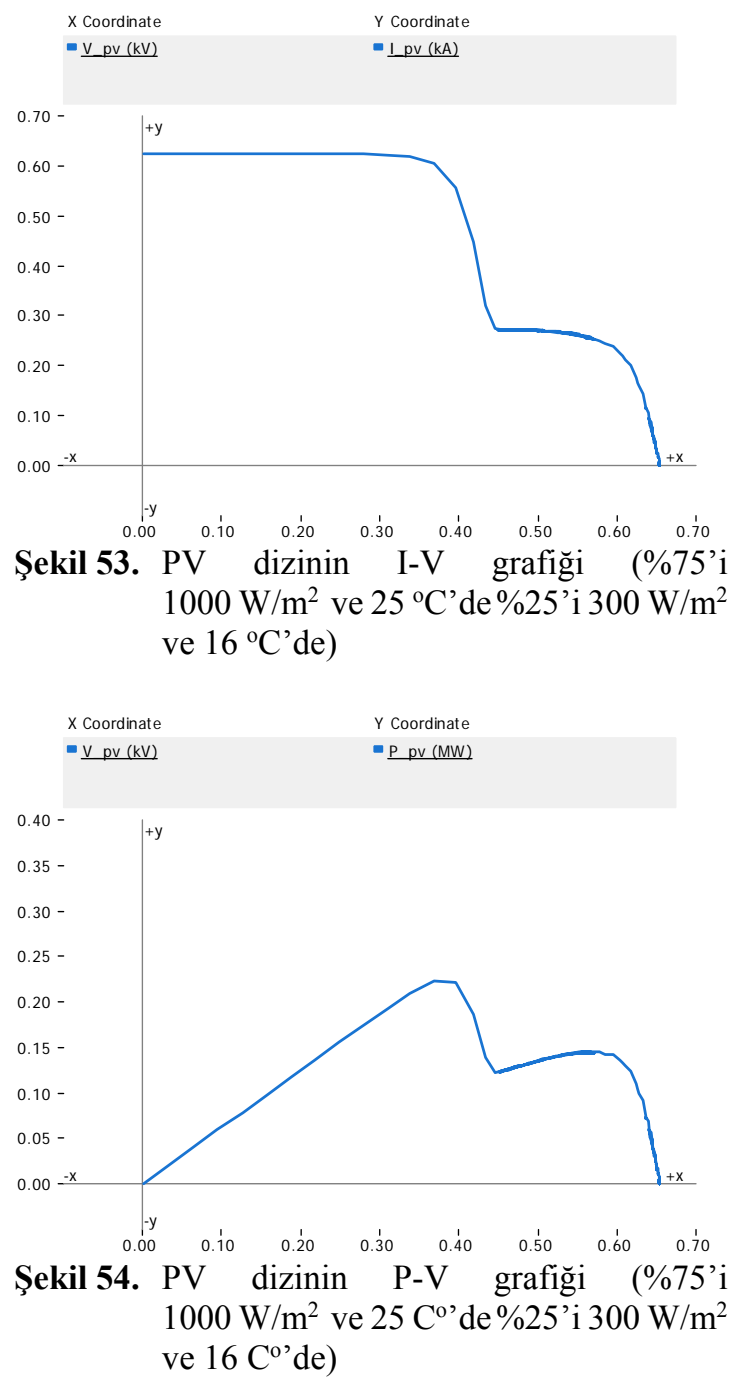

Şekil 51-54'de kısmi gölgelenme durumundan dolayı grafiklerde iki adet tepe oluştuğu gözlenmektedir. Bu tepelerden biri LMPP, diğeri GMPP olarak adlandirılır. P-V grafikleri ile 5. ve 6. Senaryolardaki PV dizin aktif güç grafikleri (Şekil 38 ve Şekil 44) karşılaş̧ırıldığında sistemin LMPP'de çalıştığı gözlenmektedir.

\section{SONUÇ}

$\mathrm{Bu}$ çalıșmada $\mathrm{PV}$, akü, lineer yük ve elektrik şebekesinden oluşan bir sistemin modellemesi ve farklı gölgelenme senaryoları için performans 
analizi gösterilmiştir. PV sistemin MPP izlemesi için P\&O algoritması kullanılmış olup bu algoritmanın PV dizinin kısmi olarak gölgelendiği senaryolarda PV dizinin yerel maksimum güç noktalarında takılıp global maksimum güç noktasına ulaşmadığı gözlenmiştir. İleriki çalışmalar için 2. Başlıkta da bahsedilen literatürde son dönemde kısmi gölgelenme koşullarında MPPT için geliştirilmiş olan yöntemler uygulanarak bu çalışmada modellenen sistemin performansının artırılabileceği öngörülmektedir.

\section{TEŞEKKÜR}

$\mathrm{Bu}$ çalışma Çukurova Üniversitesi Bilimsel Araştırma Projeleri Koordinasyon Birimince Desteklenmiştir. (Proje Numarası: 10587).

\section{KAYNAKLAR}

1. Mohapatra, A., Nayak, B., Das, P., Mohanty, K.B., 2017. A Review on MPPT Techniques of PV System Under Partial Shading Condition Renewable and Sustainable Energy Reviews, $80,854-86$

2. Ishaque, K., Salam, Z., 2013. A Review of Maximum Power Point Tracking Techniques of PV System for Uniform Insolation and Partial Shading Condition, Renewable and Sustainable Energy Reviews, 19, 475-488.

3. Guichi, A., Talha, A., Berkouk, E.M., Mekhilef, S., Gassab, S., 2018. A New Method for Intermediate Power Point Tracking for PV Generator Under Partially Shaded Conditions in Hybrid System, Solar Energy, 170, 974-987.

4. Goud, J.S., Kalpana, R., Singh, B., 2018. A Hybrid Global Maximum Power Point Tracking Technique With Fast Convergence Speed for Partial-Shaded PV Systems, IEEE Transactions on Industry Applications, 54, 5367-5376.

5. Farzaneh, J., Keypour, R., Khanesar, M.A., 2018. A New Maximum Power Point Tracking Based on Modified Firefly Algorithm for PV System Under Partial Shading Conditions, Technology and Economics of Smart Grids and Sustainable Energy, Vol. 3.
6. Tang, R., 2017. Large-scale Photovoltaic System on Green Ship and its MPPT Controlling, Solar Energy, 157, 614-628.

7. Ramyar, A., Iman-Eini, H., Farhangi, S., 2017. Global Maximum Power Point Tracking Method for Photovoltaic Arrays under Partial Shading Conditions, IEEE Transactions on Industrial Electronics, 64, 2855-2864.

8. Belhaouas, N., Cheikh, M.S.A., Agathoklis, P., Oularbi, M.R., Amrouche, B., Sedraoui, K., et al., 2017. PV Array Power Output Maximization Under Partial Shading Using New Shifted PV Array Arrangements, Applied Energy, 187, 326-337.

9. Wang, Y., Li, Y., Ruan, X., 2016. HighAccuracy and Fast-Speed MPPT Methods for PV String under Partially Shaded Conditions, IEEE Transactions on Industrial Electronics, 63, 235-245.

10. Pati, A.K., Sahoo, N.C., 2016. A New Approach in Maximum Power Point Tracking for a Photovoltaic Array With Power Management System Using Fibonacci Search Algorithm Under Partial Shading Conditions, Energy Systems, 7, 145-172.

11. Ghasemi, M. A., Mohammadian Foroushani, H., Parniani, M., 2016. Partial Shading Detection and Smooth Maximum Power Point Tracking of PV Arrays Under PSC, IEEE Transactions on Power Electronics, 31, 6281-6292

12. Sabillon, C., Franco, J.F., Rider, M.J., Romero, R., 2018. Joint Optimal Operation of Photovoltaic Units and Electric Vehicles in Residential Networks With Storage Systems: A Dynamic Scheduling Method, International Journal of Electrical Power \& Energy Systems, 103, 136-145.

13. Sani Hassan, A., Cipcigan, L., Jenkins, N., 2017. Optimal Battery Storage Operation for PV Systems with Tariff Incentives, Applied Energy, 203, 422-441.

14. Numbi, B.P., Malinga, S.J., 2017. Optimal Energy Cost and Economic Analysis of a Residential Grid-interactive Solar PV Systemcase of eThekwini Municipality in South Africa, Applied Energy, 186, 28-45.

15. Kumar, N., Hussain, I., Singh, B., Panigrahi, B.K., 2017. Single Sensor-Based MPPT of Partially Shaded PV System for Battery 
Charging by Using Cauchy and Gaussian Sine Cosine Optimization, IEEE Transactions on Energy Conversion, 32, 983-992.

16. Karimi, Y., Oraee, H., Golsorkhi, M.S., Guerrero, J.M., 2017. Decentralized Method for Load Sharing and Power Management in a PV/Battery Hybrid Source Islanded Microgrid, IEEE Transactions on Power Electronics, 32, 3525-3535.

17. Badawy M.O., Sozer Y., 2017. Power Flow Management of a Grid Tied PV-Battery System for Electric Vehicles Charging, IEEE Transactions on Industry Applications, 53, 1347-1357.

18. Mao, M., Zhou, L., Yang, Z., Zhang, Q., Zheng, C., Xie, B., Wan, Y., 2019. A Hybrid Intelligent GMPPT Algorithm for Partial Shading PV System. Control Engineering Practice, 83, 108-115.

19. Liu, S.Y., Dougal, R.A., 2002. Dynamic Multiphysics Model for Solar Array, Ieee Transactions on Energy Conversion, 17, 285-294,

20. Tremblay, O., Dessaint, L.A., Dekkiche, A.I., 2007. A Generic Battery Model for the Dynamic Simulation of Hybrid Electric Vehicles, 2007 Ieee Vehicle Power and Propulsion Conference, 1-2, 284-289. 
